Bentham OPEN The Open Orthopaedics Journal

RESEARCH ARTICLE

\title{
Psychophysical and Patient Factors as Determinants of Pain, Function and Health Status in Shoulder Disorders
}

\author{
Zakir Uddin $^{*}, 1,3$, Joy C. MacDermid ${ }^{1,2,4}$, Jaydeep Moro ${ }^{5}$, Victoria Galea ${ }^{1,1}$ and Anita R. Gross ${ }^{1}$

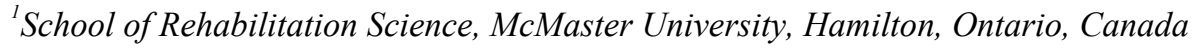 \\ ${ }^{2}$ Clinical Research Lab, Hand and Upper Limb Centre, St. Joseph's Health Centre, London, Ontario, Canada \\ ${ }^{3}$ Department of Physiotherapy, College of Health Sciences, University of Sharjah, UAE \\ ${ }^{4}$ Department of Physical Therapy, Western University, London, Ontario, Canada \\ ${ }^{5}$ Division of Orthopaedic Surgery, Departments of Surgery, McMaster University, Hamilton, Ontario, Canada
}

Received: February 08, 2016

Revised: June 04, 2016

Accepted: August 16, 2016

\begin{abstract}
:
Objective:

To estimate the extent to which psychophysical quantitative sensory test (QST) and patient factors (gender, age and comorbidity) predict pain, function and health status in people with shoulder disorders. To determine if there are gender differences for QST measures in current perception threshold (CPT), vibration threshold (VT) and pressure pain (PP) threshold and tolerance.
\end{abstract}

Design:

A cross-sectional study design.

Setting:

MacHAND Clinical Research Lab at McMaster University.

Subjects:

34 surgical and 10 nonsurgical participants with shoulder pain were recruited.

Method:

Participants completed the following patient reported outcomes: pain (Numeric Pain Rating, Pain Catastrophizing Scale, Shoulder Pain and Disability Index) and health status (Short Form-12). Participants completed QST at 4 standardized locations and then an upper extremity performance-based endurance test (FIT-HaNSA). Pearson r's were computed to determine the relationships between QST variables and patient factors with either pain, function or health status. Eight regression models were built to analysis QST's and patient factors separately as predictors of either pain, function or health status. An independent sample t-test was done to evaluate the gender effect on QST.

\section{Results:}

Greater PP threshold and PP tolerance was significantly correlated with higher shoulder functional performance on the FIT-HANSA $(\mathrm{r}=0.31-0.44)$ and lower self-reported shoulder disability $(\mathrm{r}=-0.32$ to -0.36$)$. Higher comorbidity was consistently correlated ( $\mathrm{r}$ $=0.31-0.46)$ with more pain, and less function and health status. Older age was correlated to more pain intensity and less function ( $\mathrm{r}$ $=0.31-0.57)$. In multivariate models, patient factors contributed significantly to pain, function or health status models $\left(r^{2}=0.19-0.36\right)$;

\footnotetext{
* Address correspondence to this author at the Department of Physiotherapy, College of Health Sciences, University of Sharjah, UAE; Tel: +971-6-505-7503; Fax: +971-56-505-7502; E-mails: zuddin@sharjah.ac.ae, uddinz2@mcmaster.ca, zakiru@gmail.com
} 
whereas QST did not. QST was significantly different between males and females [in PP threshold $(3.9$ vs. 6.2, p <.001) and PP tolerance (7.6 vs. 2.6, $\mathrm{p}<.001)$ and CPT $(1.6$ vs. 2.3, $\mathrm{p}=.02)]$.

\section{Conclusion:}

Psychophysical dimensions and patient factors (gender, age and comorbidity) affect self-reported and performance-based outcome measures in people with shoulder disorders.

Keywords: Abnormal sensory function, Potential risk factors, Sensory evaluation, Shoulder pain,.

\section{INTRODUCTION}

Shoulder disorders are the third most common musculoskeletal disorder [1, 2] and cause substantial disability [3, 4]. Shoulder pain contributes to a substantial socio-economic burden for patients and society [5, 7]. Systematic reviews have estimated a 1 to $3 \%$ incidence of shoulder pain and $5-47 \%$ yearly prevalence in the general population [6, 7]. The reported incidence and prevalence of shoulder pain varies according to patient factors (e.g. age, gender, and comorbidity). Older age is associated with greater shoulder pain as arthritis [8,9] and rotator cuff degeneration [9] increase over the lifespan. The prevalence of shoulder pain has been reported to be higher in females [8], whereas gender is not a factor for radiological changes in the shoulder joint after controlling for age [9]. Comorbidity has been associated with poorer pain, function, and health status in patients with chronic rotator cuff tears [10].

Chronic shoulder pain development is common, as it has been estimated to affect $11 \%$ of the working population $[11,12]$. The International Association for the Study of Pain (IASP) has defined chronic pain as a pain syndrome lasting more than 3 months [13]. The IASP recognizes chronic pain as a serious global chronic health problem with substantial economic impact [14]. Chronic musculoskeletal pain has multiple aetiologies including chronic diseases like arthritis; acute injuries like fractures [15]; or can persist following major surgery [16]. Neuropathic pain is a type of pain thought to represent pathology within the somatosensory nervous system [17] and is a challenging subset of the chronic pain population [18, 19]. Neuropathic pain often presents with hypo or hyper-sensory function (i.e. hypoesthesia or hyperesthesia) [20]. These two abnormal sensory functions are also common in chronic pain [21].

It is now recognized that chronic (persistent) pain can become a disease [9]. There is a need for appropriate assessments that will identify risk factors and promote early intervention to reduce the burden [14, 22]. Sensory abnormalities and persistent pain have been a reported risk factor for higher pain in a large population based study [23]. Psychophysical quantitative sensory testing (QST) can identify both hypo and hyper sensory function, thereby assessing small and large nerve fibers [20]. This has potential to contribute to the assessment of shoulder conditions, if it can be shown to help with diagnosis, treatment selection or prognosis.

Approaches to evaluating sensibility include methods that identify the ability to detect sensory stimuli or to perceive pain. Detection of sensory stimuli can include detection threshold or ability to discriminate different stimuli. Measurement of pain detection includes pain threshold or tolerance testing.

In musculoskeletal disorders, pain and function are primary health outcomes. Function can be measured by selfreport or performance-based tests that prior unique perspectives on the patient's ability to be functional in daily life. Previous research has established, across numerous musculoskeletal conditions, that self-reported and performancebased measures are moderately related in musculoskeletal disorders.

The main objective of this study was to estimate the extent to which QST and patient factors (age, gender, and comorbidity) predict pain, function and health status in people with shoulder disorder. The second objective of this study was to determine if there are gender differences for QST (psychophysical) measures in current perception threshold (CPT) vibration threshold (VT) and pressure pain (PP) threshold and tolerance for this patient population.

\section{MATERIALS AND METHODS}

\subsection{Study Design and Participants}

In a cross-sectional study design 34 surgical and 10 nonsurgical participants with shoulder pain were recruited. The surgical group of participants were undergoing surgery for rotator cuff tear, shoulder impingement or total shoulder joint arthroplasty, and were recruited from McMaster University affiliated orthopedic surgery clinics. The nonsurgical group of participants (with shoulder pain for more than 3 months) were recruited through flyers. The study protocol was approved by the Hamilton Integrated Research Ethics Board (a jointly constituted board of St. Joseph's Healthcare 
Hamilton, Hamilton Health Sciences and McMaster University's Faculty of Health Sciences). Informed consent was obtained from all participants prior to testing. All participants were asked to complete self-reported outcome measures and then underwent performance and quantitative sensory tests in the MacHAND Clinical Research Lab at McMaster University.

Table 1. Summary of the study measures.

\begin{tabular}{|c|c|c|c|c|}
\hline Construct & Perspective of Score & \multicolumn{2}{|c|}{ Measuring Tool } & Reliability \\
\hline \multicolumn{5}{|c|}{ Outcome (Dependent) Variables } \\
\hline Pain & $\begin{array}{l}\text { Self-report } \\
\text { Self-report }\end{array}$ & $\begin{array}{l}\text { Shoulder Pain and Disability } \\
\text { Index (SPADI) - Pain } \\
\text { Subscale [24 - 26] } \\
\text { Numeric rating scale (NRS) } \\
\text { of Pain [27 - 29] } \\
\\
\text { Pain Catastrophizing Scale } \\
\text { (PCS) [30] }\end{array}$ & 0-10 (5 pain items) & $\begin{array}{l}\text { ICC } \geq 0.89, \alpha>0.90[26] \\
\text { Sensitivity }=71 \% \text { (for score } \\
\text { of } 1 \text { ) }[27,28], \text { ICC }=.74[29]\end{array}$ \\
\hline Functional & $\begin{array}{l}\text { Self-report } \\
\text { Self-report }\end{array}$ & $\begin{array}{c}\text { Shoulder Pain and Disability } \\
\text { Index (SPADI) - Disability } \\
\text { Subscale [24 - 26, 57] } \\
\\
\text { QuickDASH (Disabilities of } \\
\text { the Arm, Shoulder and Hand) } \\
{[29,34-39]}\end{array}$ & 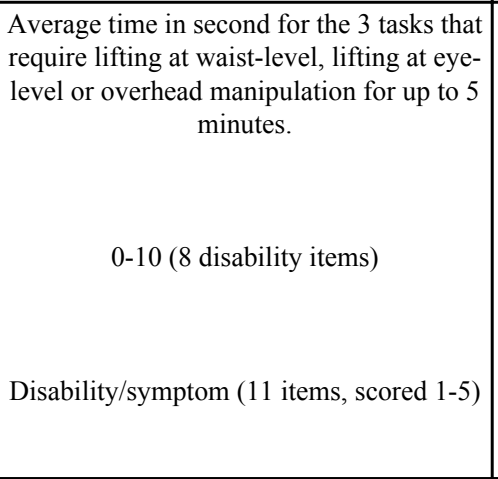 & $\begin{array}{c}\text { ICC have ranged from .79- } \\
.98[10] \\
\text { ICC } \geq .89, \alpha>.90[26]\end{array}$ \\
\hline Health Status & $\begin{array}{c}\text { Self-report: Physical } \\
\text { and Mental Component } \\
\text { Summary (PCS and } \\
\text { MCS) }\end{array}$ & SF-12 (v2 health survey) [40] & $\begin{array}{l}0-5(12 \text { items), finally PCS and MCS } \\
\text { scores are converted range of } 0 \text { to } 100\end{array}$ & $\mathrm{ICC} \geq .77, \alpha>.77[58,59]$ \\
\hline \multicolumn{5}{|c|}{ Predictor (Independent) Variables: Psychophysical factors } \\
\hline $\begin{array}{ll}\text { Pressure } & \text { Pain } \\
\text { Sensitivity } & \end{array}$ & $\begin{array}{c}\text { Pressure pain threshold } \\
\text { and pain tolerance }\end{array}$ & $\begin{array}{l}\text { Computerized JTech } \\
\text { algometer [43] }\end{array}$ & $\begin{array}{l}\text { Pressure level at uncomfortable and } \\
\text { intolerable are determined in muscle and } \\
\text { bone }\end{array}$ & $\begin{array}{c}\text { ICC range }=.73-.99[41, \\
42]\end{array}$ \\
\hline $\begin{array}{l}\text { Vibration } \\
\text { Sensation } \\
\text { Threshold }\end{array}$ & $\begin{array}{l}\text { Threshold value of } \\
\text { vibration sensation }\end{array}$ & JTech vibrometer [46] & $\begin{array}{l}\text { 50Hz Ramped protocol and threshold } \\
\text { determined in micrometers. }\end{array}$ & $\mathrm{ICC}=.86-.89[46]$ \\
\hline \begin{tabular}{l|} 
Current Perception \\
Threshold
\end{tabular} & $\begin{array}{l}\text { Threshold value of } \\
\text { current perception }\end{array}$ & $\begin{array}{c}\text { Neurometer CPT/C }[47,48, \\
54]\end{array}$ & 1-25 (R-CPT protocol, 5Hz) & $\begin{array}{c}\text { Sensitivity }=73-92 \%[47, \\
48,54]\end{array}$ \\
\hline \multicolumn{5}{|c|}{ Patient factor (Covariate ) } \\
\hline Comorbidity & Self-report & Katz comorbidity index [10] & $0-3$ (12 items score $)$ & $\mathrm{ICC}=.91[55]$ \\
\hline
\end{tabular}

Participants inclusion criteria were: age between 18-85 years, fluency in English (reading and speaking), ability to complete all assessments, complaints of pain limited to shoulder area, persistent symptoms for at least 3 months. Additional criteria for the surgical group were: shoulder pathology confirmed by a referring surgeon based on physical examination or imaging evidence, scheduled for shoulder impingement release or rotator cuff reconstruction or shoulder arthroplasty. Exclusion criteria were: any neurological disorders or pre-existing neuropathic pain as indicated by specific neuropathic pain treatment/diagnostic procedures, current pain complaints from prior shoulder surgery, history of recent shoulder fracture, tumor, cancer or infection, history of chronic pain disorder (previously diagnosed), currently under psychiatric management (from history of medication), high risk of surgery due to any comorbid condition, and patients who are unable to complete the test procedures.

\subsection{Study Measures}

All measures were summarized in Table 1, and described as follows: 


\subsubsection{Pain Measures}

\subsubsection{Shoulder Pain and Disability Index (SPADI) - Pain Subscale}

Shoulder specific pain was measured using the pain subscale of the SPADI [24 - 26]. The SPADI contains five shoulder specific pain items (pain subscale). In the pain subscale, each item is rated on a 0-10 numeric scale (no pain to worst pain imaginable) and the total score is transformed in \% (0-100). A systematic review [26] demonstrated that the SPADI is a reliable and valid (ICC $\geq .89, \alpha>.90)$ measuring tool for shoulder disorder.

\subsubsection{Numeric Rating Scale (NRS) of Pain}

The 11-point NRS of pain was used to capture the participant's level of pain. The scale is anchored from (0-10) with the phrase "no pain" to "worst imaginable pain." Patients rated their current level of pain before testing. The NRS of pain has been shown to be reliable and valid [27 - 29]. NRS of pain is a sensitive scale and good for parametric data analysis [27].

\subsubsection{Pain Catastrophizing Scale (PCS)}

It is assumed that pain catastrophizing reflects a negative coping strategy that may affect cognition around pain. Pain catastrophizing was measured with the PCS [30], which is a 13-item self-report scale. This scale measures three different categories of pain catastrophizing (e.g. rumination, magnification and helplessness) [31].

\subsubsection{Function Measures}

\subsubsection{Functional Impairment Test-Head and Neck, Shoulder, Arm (FIT-HaNSA)}

Functional performance was measured using the FIT-HaNSA that has been validated as a functional performance tests for shoulder disorders [32]. The FIT-HaNSA is a 15-minute function test for each arm with three components/levels tasks that require repeated movement of the upper limb. The testing time of each repeated task performance is up to 5 minutes. The actual duration of the patient's performance is measured by a stopwatch. The average time of the three tasks' performance is the score for the test. It was performed using the JTech JobSim System (JTECH Medical, Salt Lake City, UT, USA).

\subsubsection{Shoulder Pain and Disability Index (SPADI) - Disability Subscale}

Shoulder specific disability was measured using the disability subscale of the SPADI [24 - 26]. The SPADI contains 8 disability items (disability subscale). In the disability subscale, each item is rated on a $0-10$ numeric scale (no difficulty to so difficult requiring help) and the total score is transformed in \% (0-100).

\subsubsection{Disabilities of the Arm, Shoulder and Hand (OuickDASH)}

The Quick-DASH [34] contains 11-items from the original DASH and in early studies, has shown equivalent psychometric properties [29, 35 - 39]. The assigned values for all completed responses are summed and averaged to produce a score out of five. This value is then transformed to a $0-100$ scale by subtracting one and multiplying by 25 . A higher score is the indicator of greater disability.

\subsubsection{Health Status Measures}

\subsubsection{Short Form 12 (SF-12)}

The recognized and valid SF-12 [40] version 2 was used to measure overall health. The SF-12 consists of both physical and mental domains of 12-items. The scoring system is norm-based, and summary scores (summing across all 12-items) are obtained for each of the domains: physical component summary (PCS) score and mental component summary (MCS) score; a higher levels of health is indicated by a higher score

\subsubsection{Quantitative Sensory Testing (QST)}

\subsubsection{Pressure Pain (PP) Sensitivity}

PP threshold and PP tolerance [41 - 43] were measured using the computerized JTech algometer (JTECH Medical, Salt Lake City, UT, USA). The applied algometric pressures at an "uncomfortable" (pain threshold) and at "intolerable" 
(pain tolerance) levels were determined by patient response using a standard protocol [44, 45]. The shoulder (mid deltoid muscle) and shin (anterior aspect of tibia) of the affected side were tested (Fig. 1).

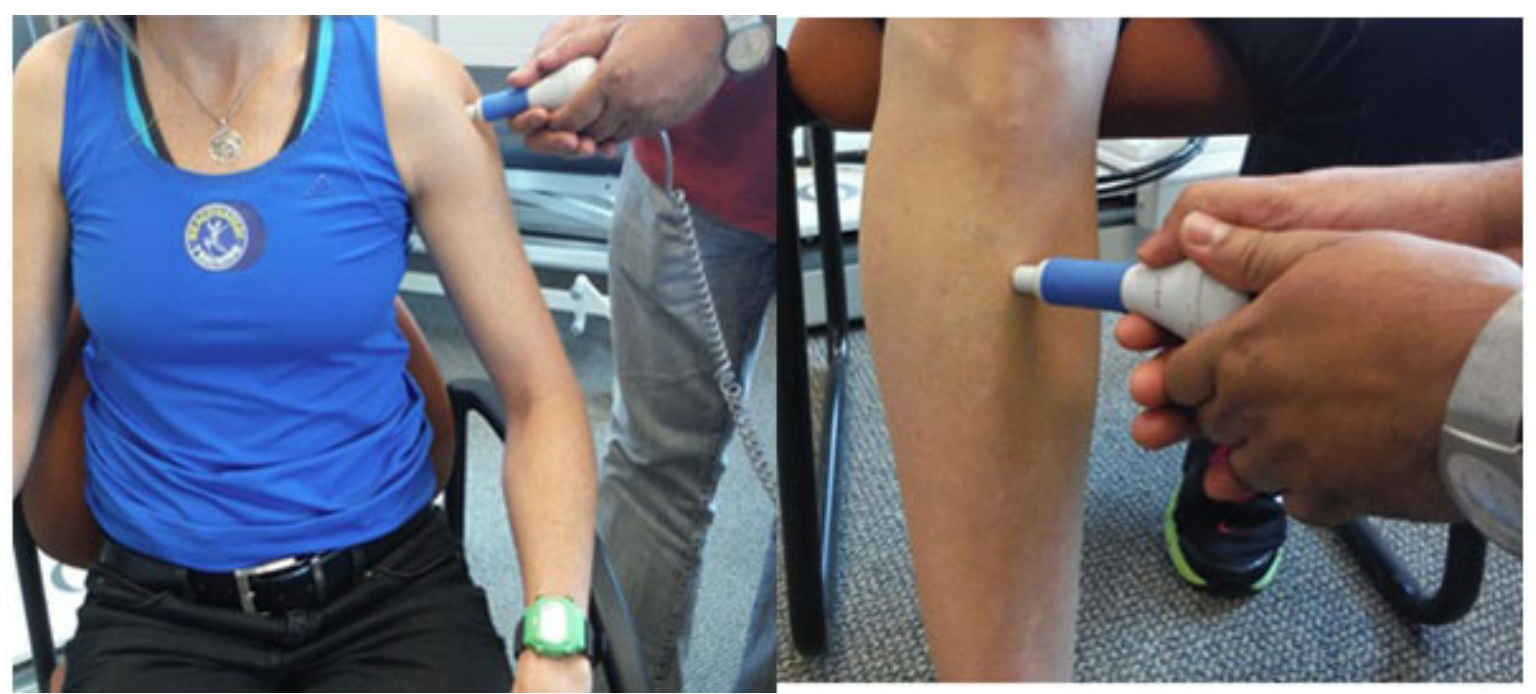

Fig. (1). The set-up for the pressure pain threshold and tolerance test (by a computerized Algometer) procedure is depicted. The test was done on the shoulder (left) and shin bone (right).

\subsubsection{Vibration Threshold (VT)}

VT was measured in the hand using a $50 \mathrm{~Hz}$ vibrometer [46]. In this test, the subject's digit is placed lightly on the device's vibrating pin. A sample stimulus is provided as practice before testing. During the test, a ramped protocol of intermittent vibration stimuli is applied to the digit. The subject indicates when the stimulus was perceived with a handheld trigger. The vibrometer's software determines a threshold score after multiple cycles. The test was performed on the middle (D3) and little (D5) fingers (Fig. 2).

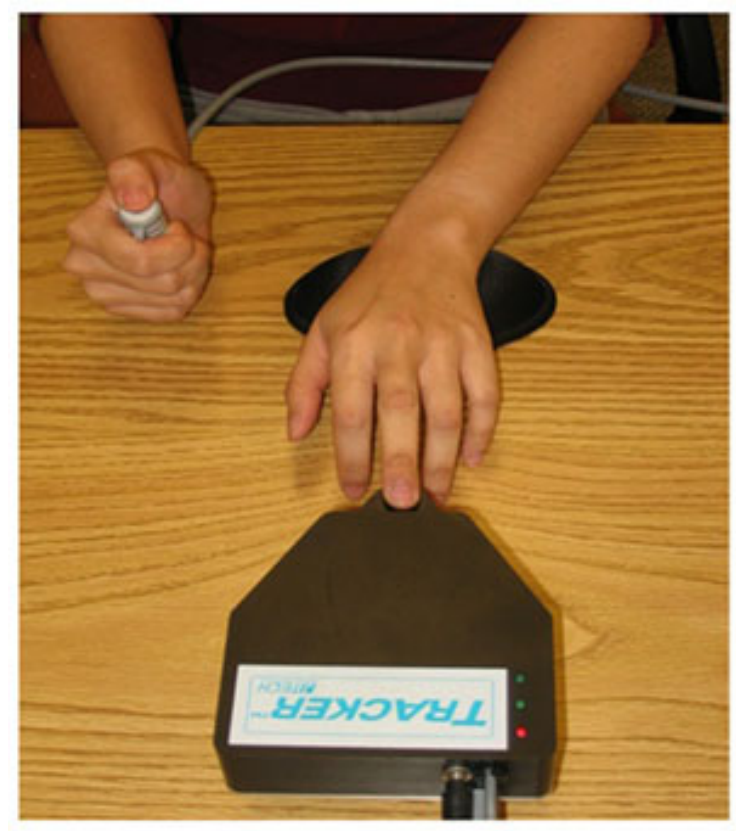

Fig. (2). Set-up of Vibrometer with $50 \mathrm{~Hz}$ stimulus. The test was done on the middle and little fingers.

\subsubsection{Current Perception Threshold (CPT)}

CPT testing [47 - 54] was performed using the Rapid Current Perception Threshold (R-CPT) protocol of the Neurometer CPT/C (Neurotron, Incorporated, Baltimore, MD, USA). The R-CPT test protocol requires the subject to 
self-administer electrical stimuli, increasing in intensity through a series of 25 predetermined levels. The subject presses and holds a button to start the test and releases the button as soon as a stimulus is detected. The test is double-blinded, and the non-noxious current is delivered via small surface electrodes placed on the medial and lateral sides of the distal phalanx. The Neurometer software determines the threshold score after multiple cycles. The test was performed at the $5 \mathrm{~Hz}$ frequency on the tip of the middle (D3) and little (D5) fingers, as well as at the shoulder (mid deltoid) (Fig. 3).

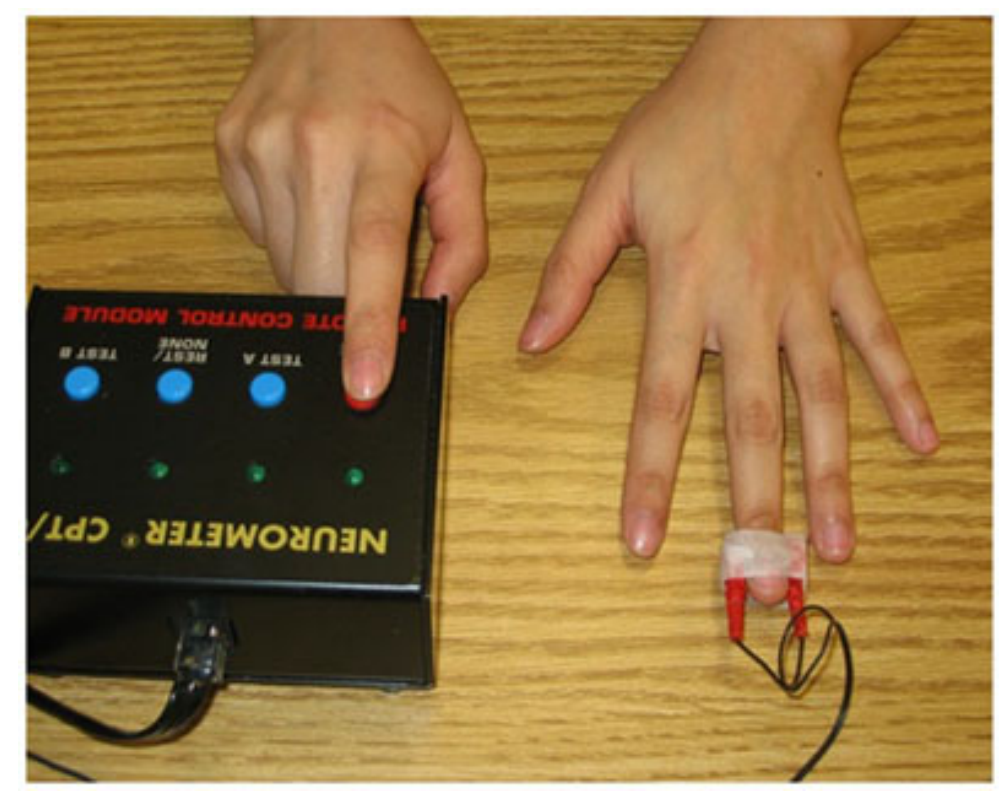

Fig. (3). The set-up for the current perception threshold (CPT) test procedure is depicted. The Rapid-CPT values (1 to 25) is obtained from the minimal strength of alternating current (between 0 to $10 \mathrm{~mA}$ ) stimulus that the patient could detect. The test was performed at the $5 \mathrm{~Hz}$ frequency on the tip of the middle (D3) and little (D5) fingers, as well as at the shoulder (mid deltoid).

\subsubsection{Patient Factor (Comorbidity Status)}

The Katz comorbidity scale was used to detect the number and severity of 12 co-morbid conditions [55, 56]. Participants are asked to indicate if they currently have the condition and whether or not they receive treatment for it, and whether activities are limited by the condition. A patient can receive a maximum of three points for each condition: one point for if they have been diagnosed with the comorbid health, one point if it requires treatment, and one point if causes activity limitation [55]. The total score is calculated by summing across 12-items [10].

\subsection{Data Analysis}

All data were entered into SPSS 17.0 software (SPSS Inc., Chicago, IL). Data quality checking was performed before statistical analysis. Descriptive statistics (e.g. skewness, kurtosis) and test of normality (Kolmogorov-Smirnov, Shapiro-Wilk, Histogram, and QQ-Plot) were conducted on all variables. Assumptions' of multiple regressions (e.g. multicollinearity and singularity, outliers, normality, linearity, homoscedasticity) were checked and met.

Means and standard deviations were calculated for all measured variables (e.g. outcome, predictor and patients factor) for both the surgical and nonsurgical groups, as well as the total sample. Pearson correlation coefficients were computed to describe the relationships between QST variables and patient factors, with pain, function or health status. Eight regression models were built to analyze QST's and patient factors separately as predictors of either pain, function or health status. An independent sample t-test (equal variance assumed) was performed to evaluate the gender effect on QST. Significance was set at $\alpha=05$.

\section{RESULTS}

All participants had shoulder pain, but were able to complete the study protocol without difficulty, including 34 patients recruited from a surgical waitlist and 10 patients recruited from the community. The age of the two patient subgroups was similar. Patients from the community had less pain, better shoulder performance and function, better health status and were predominantly female; whereas surgical patients were predominantly male as described in Table 2. 
Table 2. Participant demographics and measures and demographics, mean (standard deviation).

\begin{tabular}{|c|c|c|c|c|}
\hline Construct & Measure & Surgical group $(n=34)$ & Non-Surgical group $(\mathrm{n}=10)$ & Overall $(n=44)$ \\
\hline \multirow[t]{3}{*}{ Pain } & SPADI-Pain & $57.1(27.1)$ & $37(17)$ & $52.5(26.4)$ \\
\hline & NRS of Pain & $2.21(2.3)$ & $2.00(1.6)$ & $2.2(2.1)$ \\
\hline & PainCS & $16.7(15.6)$ & $13.7(16)$ & $16(15.5)$ \\
\hline \multirow[t]{3}{*}{ Function } & FIT-HaNSA & $158.5(95.1)$ & $183.3(65.4)$ & $164.2(89)$ \\
\hline & SPADI-Disability & $36.4(27.9)$ & $19.4(14)$ & $32.5(26.3)$ \\
\hline & QuickDASH & $38.2(21.8)$ & $23.9(19.4)$ & $34.8(21.9)$ \\
\hline \multirow[b]{2}{*}{ Health Status } & SF12-PCS & $39.5(9.8)$ & $47.8(8.5)$ & $41.4(10.1)$ \\
\hline & SF1-2MCS & $49.5(12.3)$ & $45.1(12.1)$ & $48.5(12.2)$ \\
\hline \multirow[t]{9}{*}{ Psychophysical QSTs } & PPThSh & $8.4(5.9)$ & $4.5(1.9)$ & $7.5(5.5)$ \\
\hline & PPToSh & $16.5(11.9)$ & $9.2(3.4)$ & $14.8(11)$ \\
\hline & PPThT & $7.1(3.6)$ & $4.9(2.2)$ & $6.6(3.5)$ \\
\hline & PPToT & $11.5(6.1)$ & $6.5(2.2)$ & $10.3(5.8)$ \\
\hline & VTD3 & $11.7(8.5)$ & $7(2.1)$ & $10.7(7.8)$ \\
\hline & VTD5 & $16.7(25.6)$ & $17.6(30.2)$ & $16.9(26.3)$ \\
\hline & CPTD3 & $10.6(2.9)$ & $8.6(3.6)$ & $10.1(3.1)$ \\
\hline & CPTD5 & $10.9(2.4)$ & $10(1.8)$ & $10.7(2.3)$ \\
\hline & CPTSh & $8.6(2.2)$ & $8.1(2.6)$ & $8.5(2.3)$ \\
\hline \multirow[t]{3}{*}{ Patient Factors } & Age (years) & \begin{tabular}{|c|}
$46(16.4)$ \\
\end{tabular} & $44.2(17.5)$ & $45.6(16.4)$ \\
\hline & Gender & $\mathrm{M}=25(74 \%), \mathrm{F}=9(26 \%)$ & $\mathrm{M}=2(20 \%), \mathrm{F}=8(80 \%)$ & $\mathrm{M}=27(61 \%), \mathrm{F}=17(39 \%)$ \\
\hline & Comorbidity & $4.1(4.2)$ & $3.9(1.9)$ & $4.1(3.8)$ \\
\hline \multirow[t]{3}{*}{ Other Demographics } & & & & \\
\hline & Dominant side & $\mathrm{R}=29(85 \%), \mathrm{L}=5(15 \%)$ & $\mathrm{R}=10(100 \%)$ & $\mathrm{R}=39(89 \%), \mathrm{L}=5(11 \%)$ \\
\hline & Affected side & $\mathrm{R}=13(38 \%), \mathrm{L}=21(62 \%)$ & $\mathrm{R}=5(50 \%), \mathrm{L}=4(40 \%), \mathrm{B}=1(10 \%)$ & $\begin{array}{c}\mathrm{R}=18(41 \%), \mathrm{L}=25(57 \%), \\
\mathrm{R}+\mathrm{L}=1(2 \%)\end{array}$ \\
\hline
\end{tabular}

Abbreviations: CPTD3, Current Perception Threshold at digit 3 (middle finger); CPTD5, Current Perception Threshold at digit 5 (little finger); CPTSh, Current Perception Threshold at Shoulder (mid-deltoid); DASH, Disabilities of the Arm, Shoulder and Hand; F= female; FIT-HaNSA, (Functional Impairment Test-Head and Neck, Shoulder, Arm); L, Left; M, Male; MCS, Mental Component Summary; NRS, Numeric Rating Scale; n, number of participants; PainCS, Pain Catastrophizing Scale; PCS, Physical Component Summary; PPThSh, Pressure Pain Threshold at Shoulder (mid-deltoid); PPThT, Pressure Pain Threshold at Tibia (Shinbone); PPToSh, Pressure Pain Tolerance at Shoulder (mid-deltoid); PPToT, Pressure Pain Tolerance at Tibia (Shinbone); QST, Quantitative Sensory Testing; R, Right; SF12, Short Form 12-item health survey version 2; SPADI, Shoulder Pain and Disability Index; VTD3, Vibration Threshold at digit 3 (middle finger); VTD5, Vibration Threshold at digit 5 (little finger).

The bivariate relationships between different QSTs variables or patient factors with either pain, function or health status are shown in Table 3. These correlations indicate that greater PP threshold and tolerance was associated with better shoulder functional performance $(r=0.31-0.44)$ and less self-reported shoulder disability $(r=-0.32$ to -0.36$)$. VT or CPT were not significantly related to pain, function or health status; with the single exception that VT on the small digit (D5) was correlated to NRS of pain $(r=0.50)$ and functional performance/ FIT-HANSA $(r=-0.34)$. Amongst the patient factors a higher comorbidity score was consistently correlated $(\mathrm{r}=0.31-0.46)$ with poorer pain, function and health status. Older age was correlated to more pain (except pain catastrophizing) and less function $(\mathrm{r}=0.31-0.57)$.

Table 3. The relationships between psychophysical QSTs and patient factors with either pain, function or health status $(n=44)$.

\begin{tabular}{|c|c|c|c|c|c|c|c|c|}
\hline & \multicolumn{3}{|c|}{ Pain } & \multicolumn{3}{|c|}{ Function } & \multicolumn{2}{|c|}{ Health Status } \\
\hline & SPADI- Pain & NRS of Pain & PainCS & FIT-HaNSA & SPADI -Disability & Quick-DASH & SF12-PCS & SF12-MCS \\
\hline \multicolumn{9}{|c|}{ QST variables } \\
\hline PPThSh & -.07 & -.01 & -.11 & $.31 *$ & -.23 & -.24 & .11 & .17 \\
\hline PPToSh & -.24 & -.24 & -.29 & $.32 *$ & $-.36 *$ & -.34 & .22 & .19 \\
\hline PPThT & -.08 & -.07 & -.10 & $.40 * *$ & -.25 & -.22 & .11 & .18 \\
\hline PPToT & -.14 & -.14 & -.20 & $.44 * *$ & $-.32 *$ & -.23 & .07 & .29 \\
\hline VTD3 & .14 & -.24 & -.12 & -.25 & .09 & .07 & -.11 & .19 \\
\hline VTD5 & .16 & $.50 * *$ & -.10 & $-.34 *$ & .17 & .22 & -.24 & .17 \\
\hline CPTD3 & .04 & .06 & -.16 & -.02 & -.06 & .16 & -.16 & .01 \\
\hline CPTD5 & .12 & .21 & -.14 & .21 & .004 & -.07 & .13 & .16 \\
\hline CPTSh & .16 & .10 & .14 & -.22 & .21 & .18 & -.22 & -.15 \\
\hline
\end{tabular}




\begin{tabular}{|c|c|c|c|c|c|c|c|c|}
\hline & \multicolumn{3}{|c|}{ Pain } & \multicolumn{3}{|c|}{ Function } & \multicolumn{2}{|c|}{ Health Status } \\
\hline & SPADI- Pain & NRS of Pain & PainCS & FIT-HaNSA & SPADI -Disability & Quick-DASH & SF12-PCS & SF12-MCS \\
\hline \multicolumn{9}{|c|}{ Patient Factors } \\
\hline Age & $.31 *$ & $.38 *$ & -.001 & $-.48 * *$ & $.57 * *$ & $.40 * *$ & -.30 & .08 \\
\hline Comorbidity & $31 *$ & $.31 *$ & $.37 *$ & $-35^{*}$ & $.46 * *$ & $.42 * *$ & $-.40 * *$ & $-.43 * *$ \\
\hline
\end{tabular}

Abbreviations and Symbols: CPTD3, Current Perception Threshold at digit 3 (middle finger); CPTD5, Current Perception Threshold at digit 5 (little finger); CPTSh, Current Perception Threshold at Shoulder (mid-deltoid); DASH, Disabilities of the Arm, Shoulder and Hand; FIT-HaNSA, (Functional Impairment Test-Head and Neck, Shoulder, Arm); MCS, Mental Component Summary; NRS, Numeric Rating Scale; PainCS, Pain Catastrophizing Scale; PCS, Physical Component Summary; PPThSh, Pressure Pain Threshold at Shoulder (mid-deltoid); PPThT, Pressure Pain Threshold at Tibia (Shinbone); PPToSh, Pressure Pain Tolerance at Shoulder (mid-deltoid); PPToT, Pressure Pain Tolerance at Tibia (Shinbone); QST, Quantitative Sensory Testing; SF12, Short Form 12-item health survey version 2; SPADI, Shoulder Pain and Disability Index; VTD3, Vibration Threshold at digit 3 (middle finger); VTD5, Vibration Threshold at digit 5 (little finger); ** Correlation (Pearson's r) is significant at 0.01 level; * Correlation is significant at 0.05 level. Significant correlations are bolded.

Table 4. Regression models describing psychophysical QSTs predictors of pain, function and health status (n=44).

\begin{tabular}{|c|c|c|c|c|c|c|c|c|c|c|c|c|}
\hline \multirow{2}{*}{$\begin{array}{l}\text { Construct } \\
\text { Measure }\end{array}$} & \multirow{2}{*}{ Dependent Variable } & \multicolumn{9}{|c|}{ QST Variables in the regression model: beta (p values) are shown } & \multicolumn{2}{|r|}{ Model } \\
\hline & & PPThSh & PPToSh & PPThT & PPToT & VTD3 & \begin{tabular}{|l|} 
VTD5 \\
\end{tabular} & CPTD3 & CPTD5 & CPTSh & $\mathrm{R}^{2} \mathrm{I}$ & $\mathrm{p}$ value \\
\hline \multirow[t]{3}{*}{ Pain } & SPADI-Pain & $.31(.40)$ & $-.54(.16)$ & $-.18(.68)$ & $.15(.75)$ & $.12(.50)$ & $.18(.30)$ & $.04(.82)$ & $.14(.45)$ & $.18(.35)$ & .21. & .53 \\
\hline & NRS of Pain & $.57(.09)$ & $-.55(.12)$ & $-.38(.35)$ & $.04(.92)$ & $-.28(.08)$ & $>-.28(.08)$ & $-.05 .77)$ & $.11(.50)$ & $.11(.53)$ & .33 . & .15 \\
\hline & PainCS & $.37(.36)$ & $-.68(.09)$ & $-.14(.75)$ & $.19(.69)$ & $-.19(.29)$ & $.05(.77)$ & $-.03 .88)$ & $-.10(.58)$ & $.28(.14)$ & .22 . & .51 \\
\hline \multirow[t]{3}{*}{ Function } & FIT-HaNSA & $.13(.69)$ & $-.05(.88)$ & $.09(.81)$ & $.22(.60)$ & $-.10(.51)$ & $.24(.12)$ & $-.08(.64)$ & $.13(.42)$ & $-.21(.21)$ & .34 . & .11 \\
\hline & SPADI-Disability & $.18(.61)$ & $-.51(.16)$ & $-.26(.54)$ & $.18(.69)$ & $.03(.88)$ & $.20(.23)$ & $-.03 .87)$ & $.11(.54)$ & $.29(.12)$ & .27. & .28 \\
\hline & QuickDASH & $.09(.80)$ & $-.54(.16)$ & $-.40(.34)$ & $.38(.39)$ & $-.06(.73)$ & $.05(.76)$ & .24.19) & $-.16(.38)$ & $.30(.11)$ & .28 & .29 \\
\hline \multirow[t]{2}{*}{ Health Status } & SF12-PCS & $-.34(.38)$ & $.69(.07)$ & $.66(.13)$ & $-.72(.11)$ & $-.04(.82)$ & $-.02(.90)$ & $-.17(.33)$ & $.29(.11)$ & $-.36(.05) *$ & .30 & .22 \\
\hline & SF12-MCS & $.36(.36)$ & $-.26(.50)$ & $-.51(.25)$ & $.68(.13)$ & $.32(.07)$ & $.23(.17)$ & $-.22(.23)$ & $.21(.25)$ & \begin{tabular}{|l|}
$.25(.17)$ \\
\end{tabular} & .28 & .28 \\
\hline
\end{tabular}

Abbreviations and Symbol: CPTD3, Current Perception Threshold at digit 3 (middle finger ); CPTD5, Current Perception Threshold at digit 5 (little finger ); CPTSh, Current Perception Threshold at Shoulder (mid-deltoid ); DASH, Disabilities of the Arm, Shoulder and Hand; FIT-HaNSA, (Functional Impairment Test-Head and Neck, Shoulder, Arm); MCS, Mental Component Summary; NRS, Numeric Rating Scale; PainCS, Pain Catastrophizing Scale; PCS, Physical Component Summary; PPThSh, Pressure Pain Threshold at Shoulder (mid-deltoid ); PPThT , Pressure Pain Threshold at Tibia (Shinbone ); PPToSh, Pressure Pain Tolerance at Shoulder (mid-deltoid ); PPToT, Pressure Pain Tolerance at Tibia (Shinbone ); QST, Quantitative Sensory Testing; R², Coefficient of determination; SF12, Short Form 12-item health survey version 2; SPADI, Shoulder Pain and Disability Index; VTD3, Vibration Threshold at digit 3 (middle finger ); VTD5, Vibration Threshold at digit 5 (little finger); $*$ beta is significant at 0.05 level and bolded.

Table 5. Regression models describing patient's factors predictors of pain, function and health status $(n=44)$

\begin{tabular}{|c|c|c|c|c|c|c|}
\hline \multirow{2}{*}{ Construct Measure } & \multirow{2}{*}{ Dependent Variable } & \multicolumn{3}{|c|}{ Covariates in the model: beta (p values) are shown } & \multicolumn{2}{|c|}{ Model } \\
\hline & & Age & Gender & Comorbidity & $\mathbf{R}^{2}$ & p value \\
\hline \multirow{3}{*}{ Pain } & SPADI-Pain & $.15(38)$ & $.20(.21)$ & $.32(.07)$ & .15 & .10 \\
\hline & NRS of Pain & $.27(.11)$ & $-.08(.62)$ & $.16(.37)$ & .16 & .08 \\
\hline & PainCS & $.20(.22)$ & $.16(.30)$ & $.52(.004)^{* *}$ & .19 & $.04 *$ \\
\hline \multirow{3}{*}{ Function } & FIT-HaNSA & $-.42(.01)$ & $.04(.81)$ & $-.15(.37)$ & .27 & $.01 * *$ \\
\hline & SPADI-Disability & $.43(.004)^{* *}$ & $.06(.65)$ & $.30(.06)$ & .36 & $<.001 * *$ \\
\hline & QuickDASH & $.26(.11)$ & $.14(.37)$ & $.37(.04)^{*}$ & .25 & $.01 * *$ \\
\hline \multirow{2}{*}{ Health Status } & SF12-PCS & $-.16(.32)$ & $-.20(.20)$ & $-.40(.02)^{*}$ & .21 & $.03^{*}$ \\
\hline & SF1-2MCS & $.33(.04)^{*}$ & $.07(.63)$ & $-.55(.002)^{* *}$ & .28 & $.005 \% *$ \\
\hline
\end{tabular}

Abbreviations and Symbols: DASH, Disabilities of the Arm, Shoulder and Hand; FIT-HaNSA, (Functional Impairment Test-Head and Neck, Shoulder, Arm); MCS, Mental Component Summary; NRS, Numeric Rating Scale; PainCS, Pain Catastrophizing Scale; PCS, Physical Component Summary; SPADI, Shoulder Pain and Disability Index; ${ }^{2}$, Coefficient of determination; SF12, Short Form 12-item health survey version 2; SPADI, Shoulder Pain and Disability Index; ** beta and $\mathrm{R}^{2}$ are significant at 0.01 level; * beta and $\mathrm{R}^{2}$ are significant at 0.05 level. Significant beta and $\mathrm{R}^{2}$ are bolded.

The data listed in Table 4 indicated that when multiple individual pain and sensory variables were entered as potential predictors of health outcomes, individually, none were strong predictors. The only significant prediction in these sensory models was current perception threshold as a predictor of physical health status. The total variability explained by all sensory variables ranged from $21 \%$ to $34 \%$. Contrary to expectations, the $\mathrm{R}^{2}$ for the pain measures did not exceed that obtained for function or health status measures. The regression models in Table $\mathbf{5}$ indicated that when age, gender and comorbidity (patient factors) were considered in a multivariate model of the same health outcomes, 
comorbidity was the most common predictor. Comorbidity was significantly related to pain catastrophizing, poorer Quick-DASH scores, physical and mental health status. In these multivariate models, older age was also associated with higher shoulder disability on the SPADI and better mental health status. Despite significant predictors, the overall $\mathrm{R}^{2}$ for these models ranged from $15 \%$ to $36 \%$.

The impact of gender on QST scores was indicated in Table 6. Significant mean differences (male -female) were in PP threshold (3.9-6.2, $\mathrm{p}<.001)$ and PP tolerance $(7.6-12.6, \mathrm{p}<.001)$ tests (in all locations) and CPT in the middle finger and shoulder $(1.6-2.3, \mathrm{p}=.02)$.

Table 6. Effect of gender on psychophysical/QST measure and pain reporting $(n=44)$

\begin{tabular}{|c|c|c|c|c|}
\hline Variables & $\begin{array}{c}\text { Male, } \\
\text { Mean } \pm \text { SD }\end{array}$ & $\begin{array}{c}\text { Female, } \\
\text { Mean } \pm \text { SD }\end{array}$ & $\begin{array}{l}\text { Mean Difference } \\
\text { (Male-Female) }\end{array}$ & $P$ value \\
\hline \multicolumn{5}{|l|}{$Q S T$} \\
\hline PPThSh & $10 \pm 5.7$ & $3.8 \pm 2$ & 6.2 & $<.001$ \\
\hline PPToSh & $19.7 \pm 11.2$ & $7.1 \pm 3.9$ & 12.6 & $<.001$ \\
\hline PPThT & $8.1 \pm 3.2$ & $4.1 \pm 2.3$ & 3.9 & $<.001$ \\
\hline PPToT & $13.3 \pm 5.3$ & $5.7 \pm 2.8$ & 7.6 & $<.001$ \\
\hline VTD3 & $12.5 \pm 9.2$ & $7.8 \pm 3.3$ & 4.6 & .06 \\
\hline VTD5 & $15.1 \pm 22.1$ & $19.7 \pm 32.5$ & -4.5 & .60 \\
\hline CPTD3 & $11 \pm 2.5$ & $8.7 \pm 3.6$ & 2.3 & .02 \\
\hline CPTD5 & $11.1 \pm 2.6$ & $10.2 \pm 1.5$ & .9 & .21 \\
\hline CPTSh & $9.1 \pm 1.8$ & $7.5 \pm 2.7$ & 1.6 & .02 \\
\hline \multicolumn{5}{|l|}{ Pain } \\
\hline SPADI-Pain & $52.9 \pm 25$ & $52 \pm 29.3$ & .87 & .92 \\
\hline NRS of Pain & $1.8 \pm 2.2$ & $2.7 \pm 1.9$ & -.90 & .18 \\
\hline PainCS & $16.1 \pm 14.7$ & $15.9 \pm 17.2$ & .14 & .98 \\
\hline
\end{tabular}

Abbreviations: CPTD3, Current Perception Threshold at digit 3 (middle finger); CPTD5, Current Perception Threshold at digit 5 (little finger); CPTSh, Current Perception Threshold at Shoulder (mid-deltoid); SPADI, Shoulder Pain and Disability Index; NRS, Numeric Rating Scale; PainCS, Pain Catastrophizing Scale PPThSh, Pressure Pain Threshold at Shoulder (mid-deltoid); PPThT, Pressure Pain Threshold at Tibia (Shinbone); PPToSh, Pressure Pain Tolerance at Shoulder (mid-deltoid); PPToT, Pressure Pain Tolerance at Tibia (Shinbone); QST, Quantitative Sensory Testing; SD, Standard Deviation; VTD3, Vibration Threshold at digit 3 (middle finger); VTD5, Vibration Threshold at digit 5 (little finger). Significant mean differences and $\mathrm{p}$ values are bolded.

\section{DISCUSSION}

The study provided preliminary evidence suggesting that pain threshold and tolerance affect functional performance in people with shoulder pain; and personal factors like age, gender, and comorbid health conditions play a larger and more consistent role. The impact of isolated pain and sensory variables was less evident in multivariate modeling where despite explaining $34 \%$ of the functional performance score, significant individual predictors were not identified. Conversely, when examining age, gender and comorbidity in multivariate models, although higher $\mathrm{R}^{2}$ values were not achieved, the significance of comorbidity as a determinant of pain catastrophizing, self-reported function and health status was identified. Although males demonstrated higher pain threshold and tolerance, gender was not associated with differences in pain, function or health status when considering multivariate modeling. This indicates the pain threshold in absolute terms may not relate to pain experienced or function, and the relationships between pain threshold and function should be analyzed in a sex-differentiated analysis. Future multivariate models should be powered sufficiently to allow for separate modeling of males and females to identify the true impact of QST on functional outcomes; and to see if the relationships are similar for males and females. Gender differences in QST may have masked associations between QST and the functional outcomes in this study, although including gender in the model should at least partially control for gender effects.

The current stimulus of QST (i.e. CPT) was not correlated to pain, function or health status at any of the three sites tested by bivariate correlations. We used $5 \mathrm{~Hz} \mathrm{CPT}$, which is neuroselective to assess small fibers (C fiber) that carry pain information [47, 48, 54]. In multivariate modeling of all QST with potential predictor, it was the only one to demonstrate a significant relationship with physical health status. Our previous studies supported consistency, moderate construct and discriminative validity, good specificity, and moderate sensitivity of CPT in neck disorders [47, 60]. Since previous studies have suggested that CPT has moderate reliability, this may have mitigated the strength of the associations. VT was not related to the most of the variables of pain, function or health status. Although VT on the little 
finger was positively correlated to pain intensity and negatively correlated to functional performance, we cannot be confident of the clinical importance of these findings since the associations were not consistent. Previous research has demonstrated chronic diffuse upper limb pain is associated with an elevation of VT [61].

Older age was related to more shoulder pain without any indication of a pain catastrophizing effect. This concurs with previous studies integrating greater shoulder pathology with age [8,9]. Older age was also associated with poorer self-reported shoulder function and performance. Since there is an increasing prevalence and severity of shoulder pathology with age, the impact of shoulder pain on function in older adults is a serious concern. Comorbid conditions were negatively related to pain, function and health status in this study. This is in agreement with a previous study that reported that comorbidities negatively impact on preoperative pain, function, and health status in patients with chronic rotator cuff tears [10]. This study adds that comorbidity also increases pain catastrophizing. This is consistent with our emerging understanding of pain catastrophizing, which can be affected by genetic, physical and psychological characteristics as well as previous negative experiences with recovery [62, 63].

The relatively small sample precluded us testing interactions between QST and other variables. However, a recent systemic review and meta-analysis demonstrated that QST poorly explains pain and disability (function) [64] suggesting that the effects may be small and inconsistent. This suggests adoption of QST in evaluation of shoulder disorders would be premature before substantive empirical evidence supports the usefulness of this evaluation. The static QST measures used in the study provide a limited perspective on a complex pain processing system [20]. It has been suggested that dynamic QST is better as it assesses the spatial and temporal summation as well as descending modulation of pain [20]. In addition, suprathreshold pain processing can be assessed by magnitude rating for a suprathreshold stimulus [20]. We used threshold and tolerance parameter for QST measures in this study because these are commonly used in clinical practice. However, stimulus intensity/magnitude rating parameters of QST may be more relevant to clinical features (e.g. pain, function).

Our findings reaffirm the importance of patient factors in explaining pain, self-reported and performance-based function. Previous studies have reported that age is associated with greater shoulder pain and degeneration [8,9] and age is a significant covariate for QST [65]. Although, QST modalities are found as reliable and valid for clinical assessment in musculoskeletal pain disorders [66, 67 - 72], and clinical uses have been suggested [67 - 74].

Gender is acknowledged as an important consideration in shoulder conditions because of differences in prevalence of different shoulder conditions by gender. For example, the prevalence and incidence of shoulder pain have been reported higher in females than males [9]. Gender has been reported to be independent of radiological/degenerative changes [8]. Furthermore, gender differences in pain threshold and tolerance are well accepted [61, 66, 75, 76]. This study also demonstrates that QST measures are more sensitive (lower threshold) in female. Specifically, PP threshold and tolerance were significantly lower in females. Previous studies on QST has indicated pain thresholds are lower in female than male $[61,66,75,76]$ and detection thresholds were independent of gender [75]. All PP threshold and tolerance test scores were lower in female than male, although some detection threshold based tests (e.g. VT, CPT) were gender independent in our study. The greater sensitivity of females to pain threshold and pain tolerance may reflect differences in how sensory inputs are received at the tissue level or how they are processed from the periphery to the brain. However, this study indicates that gender differences in pain threshold and tolerance may not necessarily lead to gender differences in shoulder related health outcomes including pain, function or health status. This differential suggests that gender needs to be carefully considered when examining shoulder disorders, and that all hypotheses should be tested separately between male and female subject to assure that conclusions made apply across genders. Again, these requirements suggest the need for larger sample sizes; and prespecified gender analyses.

The main limitation of this study was that our sample was insufficient to explore the interactions and sexdisaggregated analyses that our initial analyses suggested might be informative. However, we were able to establish some important associations between both sensory and patient factors that should direct the nature of future studies. These recommendations include modelling of comorbid health, age, and sensory variables in more homogeneous shoulder conditions and with sufficient sample sizes that interactions and sex-disaggregated analyses can be performed

\section{CONCLUSION}

This cross sectional descriptive study suggests pressure pain threshold and tolerance may have a small to moderate role association with self-reported and performance-based outcome measures (e.g. pain, function and health status) for shoulder disorders. However, our findings suggest that PP threshold and tolerance tests are gender dependent, and that 
age and comorbidity also affect these outcomes. Future studies should focus on defining these more complex relationships and may consider using alternative sensory evaluations including dynamic QST and pain magnitude rating (for a suprathreshold stimulus) to elucidate the relationship between suprathreshold pain processing, descending control or central integration of pain and clinical features of shoulder pain.

\section{LIST OF ABBREVIATIONS:}

$\begin{array}{lll}\text { CPT } & = & \text { Current Perception Threshold } \\ \text { IASP } & = & \text { International Association for the Study of Pain } \\ \text { ICC } & = & \text { Intraclass Correlation Coefficient } \\ \text { NRS } & = & \text { Numeric Rating Scale } \\ \text { PCS } & = & \text { pain catastrophizing scale } \\ \text { PP } & = & \text { Pressure Pain } \\ \text { QST } & = & \text { Quantitative Sensory Testing } \\ \text { r } & = & \text { Pearson r correlation } \\ \text { SPADI } & = & \text { Shoulder Pain and Disability Index } \\ \text { Shoulder, Arm (FIT-HaNSA) } & = & \text { Functional Impairment Test-Head and Neck } \\ \text { Shoulder and Hand (QuickDASH) } & = & \text { Quick Disability Subscale of Disabilities of the Arm } \\ \text { VT } & = & \text { Vibration Threshold }\end{array}$

\section{AUTHORS' CONTRIBUTION}

Zakir Uddin conceptualized the research question, study design, data collection, data analyses and prepared the draft of the manuscript. Dr. Joy MacDermid provided expertise facility network with lab support for data collection, refined objectives and design of the study and edited the manuscript. Dr. Victoria Galea and Ms. Anita R Gross provided their content expertise and edited the manuscript. Dr. Jaydeep Moro assisted data collection by referring his scheduled surgical patients to the lab.

\section{CONFLICT OF INTEREST}

We, the authors of the manuscript, do not have a direct/indirect financial relation with the commercial/noncommercial identities mentioned in the paper that might lead to a conflict of interests.

\section{ACKNOWLEDGEMENTS}

Zakir Uddin was supported by the McMaster University School of Rehabilitation Science Graduate Scholarship, Canadian National Graduate Scholarship in Rehabilitation Science and Islamic Development Bank Merit scholarship for PhD study. Dr. Joy C. MacDermid is supported by a CIHR Chair award (Gender in Measurement and Rehabilitation of Musculoskeletal Work Disability) and the Dr. James Roth Research Chair in Musculoskeletal Measurement and Knowledge Translation.

\section{REFERENCES}

[1] Parsons S, Breen A, Foster NE, et al. Prevalence and comparative troublesomeness by age of musculoskeletal pain in different body locations. Fam Pract 2007; 24(4): 308-16. [http://dx.doi.org/10.1093/fampra/cmm027] [PMID: 17602173]

[2] Laslett LL, Burnet SP, Jones JA, Redmond CL, McNeil JD. Musculoskeletal morbidity: the growing burden of shoulder pain and disability and poor quality of life in diabetic outpatients. Clin Exp Rheumatol 2007; 25(3): 422-9. [PMID: 17631739]

[3] Badcock LJ, Lewis M, Hay EM, McCarney R, Croft PR. Chronic shoulder pain in the community: a syndrome of disability or distress? Ann Rheum Dis 2002; 61(2): 128-31.

[http://dx.doi.org/10.1136/ard.61.2.128] [PMID: 11796398]

[4] Pope DP, Croft PR, Pritchard CM, Silman AJ. Prevalence of shoulder pain in the community: the influence of case definition. Ann Rheum Dis 1997; 56(5): 308-12.

[http://dx.doi.org/10.1136/ard.56.5.308] [PMID: 9175931]

[5] van der Heijden GJ. Shoulder disorders: A state-of-the-art review. Pract Res Clin Rheumatol 1999; 13(2): $287-309$. [http://dx.doi.org/10.1053/berh.1999.0021] 
[6] Luime JJ, Koes BW, Hendriksen IJ, et al. Prevalence and incidence of shoulder pain in the general population; a systematic review. Scand J Rheumatol 2004; 33(2): 73-81. [http://dx.doi.org/10.1080/03009740310004667] [PMID: 15163107]

[7] Kuijpers T, van der Windt DA, van der Heijden GJ, Bouter LM. Systematic review of prognostic cohort studies on shoulder disorders. Pain 2004; 109(3): 420-31. [http://dx.doi.org/10.1016/j.pain.2004.02.017] [PMID: 15157703]

[8] Bonsell S, Pearsall AW IV, Heitman RJ, Helms CA, Major NM, Speer KP. The relationship of age, gender, and degenerative changes observed on radiographs of the shoulder in asymptomatic individuals. J Bone Joint Surg Br 2000; 82(8): 1135-9. [http://dx.doi.org/10.1302/0301-620X.82B8.10631] [PMID: 11132273]

[9] Cassou B, Derriennic F, Monfort C, Norton J, Touranchet A. Chronic neck and shoulder pain, age, and working conditions: longitudinal results from a large random sample in France. Occup Environ Med 2002; 59(8): 537-44. [http://dx.doi.org/10.1136/oem.59.8.537] [PMID: 12151610]

[10] Tashjian RZ, Henn RF, Kang L, Green A. The effect of comorbidity on self-assessed function in patients with a chronic rotator cuff tear. J Bone Joint Surg Am 2004; 86-A(2): 355-62. [PMID: 14960682]

[11] McBeth J, Jones K. Epidemiology of chronic musculoskeletal pain. Best Pract Res Clin Rheumatol 2007; 21 (3): 403-25. [http://dx.doi.org/10.1016/j.berh.2007.03.003] [PMID: 17602991]

[12] Herin F, Vézina M, Thaon I, Soulat JM, Paris C. Predictors of chronic shoulder pain after 5 years in a working population. Pain 2012; 153(11): 2253-9.

[http://dx.doi.org/10.1016/j.pain.2012.07.024] [PMID: 22940463]

[13] Merskey H, Bogduk N. Classification of chronic pain: descriptions of chronic pain syndromes and definition of pain terms. $2^{\text {nd }}$ ed. Seattle: IASP 1994.

[14] PainSummit 2010. Available at, http://www.iasp-pain.org/Content/NavigationMenu/Advocacy/DeclarationofMontr233al/default.htm

[15] MacDermid JC, Donner A, Richards RS, Roth JH. Patient versus injury factors as predictors of pain and disability six months after a distal radius fracture. J Clin Epidemiol 2002; 55(9): 849-54. [http://dx.doi.org/10.1016/S0895-4356(02)00445-6] [PMID: 12393071]

[16] Macrae WA. Chronic post-surgical pain: 10 years on. Br J Anaesth 2008; 101(1): 77-86. [http://dx.doi.org/10.1093/bja/aen099] [PMID: 18434337]

[17] IASP Taxonomy. Available at: http://www.iasp-pain.org/Taxonomy

[18] Perkins FM, Kehlet H. Chronic pain as an outcome of surgery. A review of predictive factors. Anesthesiology 2000; 93(4): 1123-33. [http://dx.doi.org/10.1097/00000542-200010000-00038] [PMID: 11020770]

[19] Costigan M, Scholz J, Woolf CJ. Neuropathic pain: a maladaptive response of the nervous system to damage. Annu Rev Neurosci 2009; 32: $1-32$.

[http://dx.doi.org/10.1146/annurev.neuro.051508.135531] [PMID: 19400724]

[20] Arendt-Nielsen L, Yarnitsky D. Experimental and clinical applications of quantitative sensory testing applied to skin, muscles and viscera. J Pain 2009; 10(6): 556-72. [http://dx.doi.org/10.1016/j.jpain.2009.02.002] [PMID: 19380256]

[21] Maier C, Baron R, Tölle TR, et al. Quantitative sensory testing in the German Research Network on Neuropathic Pain (DFNS): somatosensory abnormalities in 1236 patients with different neuropathic pain syndromes. Pain 2010; 150(3): $439-50$. [http://dx.doi.org/10.1016/j.pain.2010.05.002] [PMID: 20627413]

[22] Scholz J, Woolf CJ. Can we conquer pain? Nat Neurosci 2002; 5(Suppl.): 1062-7. [http://dx.doi.org/10.1038/nn942] [PMID: 12403987]

[23] Johansen A, Romundstad L, Nielsen CS, Schirmer H, Stubhaug A. Persistent postsurgical pain in a general population: prevalence and predictors in the Tromsø study. Pain 2012; 153(7): 1390-6. [http://dx.doi.org/10.1016/j.pain.2012.02.018] [PMID: 22445291]

[24] Roach KE, Budiman-Mak E, Songsiridej N, Lertratanakul Y. Development of a shoulder pain and disability index. Arthritis Care Res 1991; 4(4): 143-9.

[http://dx.doi.org/10.1002/art.1790040403] [PMID: 11188601]

[25] MacDermid JC, Solomon P, Prkachin K. The shoulder pain and disability index demonstrates factor, construct and longitudinal validity. BMC Musculoskelet Disord 2006; 7(1): 12. [http://dx.doi.org/10.1186/1471-2474-7-12] [PMID: 16472394]

[26] Roy JS, MacDermid JC, Woodhouse LJ. Measuring shoulder function: a systematic review of four questionnaires. Arthritis Rheum 2009; 61(5): 623-32.

[http://dx.doi.org/10.1002/art.24396]

[27] Williamson A, Hoggart B. Pain: a review of three commonly used pain rating scales. J Clin Nurs 2005; $14(7)$ : $798-804$. [http://dx.doi.org/10.1111/j.1365-2702.2005.01121.x] [PMID: 16000093] 
[28] Krebs EE, Carey TS, Weinberger M. Accuracy of the pain numeric rating scale as a screening test in primary care. J Gen Intern Med 2007; 22(10): 1453-8 [http://dx.doi.org/10.1007/s11606-007-0321-2] [PMID: 17668269]

[29] Mintken PE, Glynn P, Cleland JA. Psychometric properties of the shortened disabilities of the arm, shoulder, and hand questionnaire (QuickDASH) and numeric pain rating scale in patients with shoulder pain. J Shoulder Elbow Surg 2009; 18(6): 920-6. [http://dx.doi.org/10.1016/j.jse.2008.12.015] [PMID: 19297202]

[30] Sullivan HJ, Bishop SR, Pivik J. The Pain Catastrophizing Scale: development and validation. Psychol Assess 1995; 7: 524-32. [http://dx.doi.org/10.1037/1040-3590.7.4.524]

[31] Osman A, Barrios FX, Gutierrez PM, Kopper BA, Merrifield T, Grittmann L. The Pain Catastrophizing Scale: further psychometric evaluation with adult samples. J Behav Med 2000; 23(4): 351-65. [http://dx.doi.org/10.1023/A:1005548801037] [PMID: 10984864]

[32] MacDermid JC, Ghobrial M, Quirion KB, et al. Validation of a new test that assesses functional performance of the upper extremity and neck (FIT-HaNSA) in patients with shoulder pathology. BMC Musculoskelet Disord 2007; 8: 42. [http://dx.doi.org/10.1186/1471-2474-8-42] [PMID: 17509150]

[33] Osman A, Barrios FX, Kopper BA, Hauptmann W, Jones J, O’Neill E. Factor structure, reliability, and validity of the Pain Catastrophizing Scale. J Behav Med 1997; 20(6): 589-605. [http://dx.doi.org/10.1023/A:1025570508954] [PMID: 9429990]

[34] Beaton DE, Wright JG, Katz JN. Development of the QuickDASH: comparison of three item-reduction approaches. J Bone Joint Surg Am 2005; 87(5): 1038-46

[http://dx.doi.org/10.2106/JBJS.D.02060] [PMID: 15866967]

[35] Fayad F, Lefevre-Colau MM, Gautheron V, et al. Reliability, validity and responsiveness of the French version of the questionnaire Quick Disability of the Arm, Shoulder and Hand in shoulder disorders. Man Ther 2009; 14(2): 206-12. [http://dx.doi.org/10.1016/j.math.2008.01.013] [PMID: 18436467]

[36] Wu A, Edgar DW, Wood FM. The QuickDASH is an appropriate tool for measuring the quality of recovery after upper limb burn injury. Burns 2007; 33(7): 843-9. [http://dx.doi.org/10.1016/j.burns.2007.03.015] [PMID: 17686586]

[37] Matheson LN, Melhorn JM, Mayer TG, Theodore BR, Gatchel RJ. Reliability of a visual analog version of the QuickDASH. J Bone Joint Surg Am 2006; 88(8): 1782-7.

[http://dx.doi.org/10.2106/JBJS.F.00406] [PMID: 16882902]

[38] Imaeda T, Toh S, Wada T, et al. Validation of the Japanese society for surgery of the hand version of the quick disability of the arm, shoulder, and hand (QuickDASH-JSSH) questionnaire. J Orthop Sci 2006; 11(3): 248-53. [http://dx.doi.org/10.1007/s00776-006-1013-1] [PMID: 16721524]

[39] Gummesson C, Ward MM, Atroshi I. The shortened disabilities of the arm, shoulder and hand questionnaire (QuickDASH): validity and reliability based on responses within the full-length DASH. BMC Musculoskelet Disord 2006; 7: 44 [http://dx.doi.org/10.1186/1471-2474-7-44] [PMID: 16709254]

[40] Riddle DL, Lee KT, Stratford PW. Use of SF-36 and SF-12 health status measures: a quantitative comparison for groups versus individual patients. Med Care 2001; 39(8): 867-78. [http://dx.doi.org/10.1097/00005650-200108000-00012] [PMID: 11468505]

[41] Chesterton LS, Sim J, Wright CC, Foster NE. Interrater reliability of algometry in measuring pressure pain thresholds in healthy humans, using multiple raters. Clin J Pain 2007; 23(9): 760-6. [http://dx.doi.org/10.1097/AJP.0b013e318154b6ae] [PMID: 18075402]

[42] Bernhardt O, Schiffman EL, Look JO. Reliability and validity of a new fingertip-shaped pressure algometer for assessing pressure pain thresholds in the temporomandibular joint and masticatory muscles. J Orofac Pain 2007; 21(1): 29-38. [PMID: 17312639]

[43] Kosek E, Ekholm J, Nordemar R. A comparison of pressure pain thresholds in different tissues and body regions. Long-term reliability of pressure algometry in healthy volunteers. Scand J Rehabil Med 1993; 25(3): 117-24. [PMID: 8248762]

[44] Walton DM, Macdermid JC, Nielson W, Teasell RW, Nailer T, Maheu P. A descriptive study of pressure pain threshold at 2 standardized sites in people with acute or subacute neck pain. J Orthop Sports Phys Ther 2011; 41(9): 651-7. [http://dx.doi.org/10.2519/jospt.2011.3667] [PMID: 21885907]

[45] Finocchietti S, Andresen T, Arendt-Nielsen L, Graven-Nielsen T. Pain evoked by pressure stimulation on the tibia bone - influence of probe diameter on tissue stress and strain. Eur J Pain 2012; 16(4): 534-42. [http://dx.doi.org/10.1016/j.ejpain.2011.08.001] [PMID: 22396082]

[46] Hubbard MC, MacDermid JC, Kramer JF, Birmingham TB. Quantitative vibration threshold testing in carpal tunnel syndrome: analysis strategies for optimizing reliability. J Hand Ther 2004; 17(1): 24-30. [http://dx.doi.org/10.1197/j.jht.2003.10.004] [PMID: 14770135]

[47] Uddin Z, MacDermid JC, Galea V, Gross AR, Pierrynowski MR. The current perception threshold test differentiates categories of mechanical 
neck disorder. J Orthop Sports Phys Ther 2014; 44(7): 532-540, C1. [http://dx.doi.org/10.2519/jospt.2014.4691] [PMID: 24981222]

[48] Katims JJ, Rouvelas P, Sadler BT, Weseley SA. Current perception threshold. Reproducibility and comparison with nerve conduction in evaluation of carpal tunnel syndrome. ASAIO Trans 1989; 35(3): 280-4. [http://dx.doi.org/10.1097/00002480-198907000-00034] [PMID: 2557064]

[49] Katims JJ, Patil AS, Rendell M, et al. Current perception threshold screening for carpal tunnel syndrome. Arch Environ Health 1991; 46(4): 207-12. [http://dx.doi.org/10.1080/00039896.1991.9937449] [PMID: 2069428]

[50] Nishimura A, Ogura T, Hase H, et al. Evaluation of sensory function after median nerve decompression in carpal tunnel syndrome using the current perception threshold test. J Orthop Sci 2003; 8(4): 500-4. [http://dx.doi.org/10.1007/s00776-003-0666-2] [PMID: 12898300]

[51] Pitei DL, Watkins PJ, Stevens MJ, Edmonds ME. The value of the Neurometer in assessing diabetic neuropathy by measurement of the current perception threshold. Diabet Med 1994; 11(9): 872-6. [http://dx.doi.org/10.1111/j.1464-5491.1994.tb00371.x] [PMID: 7705025]

[52] Prendergast JJ, Miranda G, Sanchez M. Improvement of sensory impairment in patients with peripheral neuropathy. Endocr Pract 2004; 10(1): 24-30. [http://dx.doi.org/10.4158/EP.10.1.24] [PMID: 15251618]

[53] Rendell MS, Katims JJ, Richter R, Rowland F. A comparison of nerve conduction velocities and current perception thresholds as correlates of clinical severity of diabetic sensory neuropathy. J Neurol Neurosurg Psychiatry 1989; 52(4): 502-11. [http://dx.doi.org/10.1136/jnnp.52.4.502] [PMID: 2738593]

[54] Weseley SA, Sadler B, Katims JJ. Current perception: preferred test for evaluation of peripheral nerve integrity. ASAIO Trans 1988; 34(3): 188-93. [PMID: 3196507]

[55] Katz JN, Chang LC, Sangha O, Fossel AH, Bates DW. Can comorbidity be measured by questionnaire rather than medical record review? Med Care 1996; 34(1): 73-84.

[http://dx.doi.org/10.1097/00005650-199601000-00006] [PMID: 8551813]

[56] Sangha O, Stucki G, Liang MH, Fossel AH, Katz JN. The Self-Administered Comorbidity Questionnaire: a new method to assess comorbidity for clinical and health services research. Arthritis Rheum 2003; 49(2): 156-63. [http://dx.doi.org/10.1002/art.10993] [PMID: 12687505]

[57] Kumta P, MacDermid JC, Mehta SP, Stratford PW. The FIT-HaNSA demonstrates reliability and convergent validity of functional performance in patients with shoulder disorders. J Orthop Sports Phys Ther 2012; 42(5): 455-64. [http://dx.doi.org/10.2519/jospt.2012.3796] [PMID: 22281818]

[58] Luo X, George ML, Kakouras I, et al. Reliability, validity, and responsiveness of the short form 12-item survey (SF-12) in patients with back pain. Spine 2003; 28(15): 1739-45.

[http://dx.doi.org/10.1097/01.BRS.0000083169.58671.96] [PMID: 12897502]

[59] Salyers MP, Bosworth HB, Swanson JW, Lamb-Pagone J, Osher FC. Reliability and validity of the SF-12 health survey among people with severe mental illness. Med Care 2000; 38(11): 1141-50. [http://dx.doi.org/10.1097/00005650-200011000-00008] [PMID: 11078054]

[60] Uddin Z, MacDermid JC, Galea V, et al. Reliability indices, limits of agreement and construct validity of current perception threshold test in mechanical neck disorder. Crit Rev Phys Rehabil Med 2013; 25(3-4): 25-37. [http://dx.doi.org/10.1615/CritRevPhysRehabilMed.2013007969]

[61] Sandén H, Wallin BG, Hagberg M. Chronic pain has a small influence and mood has no influence on vibrotactile perception thresholds among working women. Muscle Nerve 2010; 42(3): 401-9. [http://dx.doi.org/10.1002/mus.21697] [PMID: 20564595]

[62] Wideman TH, Asmundson GG, Smeets RJ, et al. Rethinking the fear avoidance model: toward a multidimensional framework of pain-related disability. Pain 2013; 154(11): 2262-5. [http://dx.doi.org/10.1016/j.pain.2013.06.005] [PMID: 23748115]

[63] Wideman TH, Sullivan MJ. Differential predictors of the long-term levels of pain intensity, work disability, healthcare use, and medication use in a sample of workers' compensation claimants. Pain 2011; 152(2): 376-83. [http://dx.doi.org/10.1016/j.pain.2010.10.044] [PMID: 21147513]

[64] Hübscher M, Moloney N, Leaver A, Rebbeck T, McAuley JH, Refshauge KM. Relationship between quantitative sensory testing and pain or disability in people with spinal pain-a systematic review and meta-analysis. Pain 2013; 154(9): 1497-504. [http://dx.doi.org/10.1016/j.pain.2013.05.031] [PMID: 23711482]

[65] Costantini M, Tunks K, Wyatt C, Zettel H, MacDermid JC. Age and upper limb tension testing affects current perception thresholds. J Hand Ther 2006; 19(3): 307-16 [http://dx.doi.org/10.1197/j.jht.2006.04.015] [PMID: 16861130]

[66] Uddin Z, MacDermid JC, Woodhouse LJ, Triano JJ, Galea V, Gross AR. The effect of pressure pain sensitivity and patient factors on selfreported pain-disability in patients with chronic neck pain. Open Orthop J 2014; 8: 302-9. 
[http://dx.doi.org/10.2174/1874325001408010302] [PMID: 25320651]

[67] Uddin Z, MacDermid J, Packham T. The ten test for sensation. J Physiother 2013; 59(2): 132-2. [http://dx.doi.org/10.1016/S1836-9553(13)70171-1] [PMID: 23663804]

[68] Uddin Z, Macdermid J, Packham T. Ice-water (cold stress) immersion testing. J Physiother 2013; 59(4): $277-7$. [http://dx.doi.org/10.1016/S1836-9553(13)70211-X] [PMID: 24287228]

[69] Uddin Z, MacDermid JC, Galea V, et al. Reliability indices, limits of agreement and construct validity of current perception threshold test in mechanical neck disorder. Crit Rev Phys Rehabil Med 2013; 25(3-4): 25-37. [http://dx.doi.org/10.1615/CritRevPhysRehabilMed.2013007969]

[70] Uddin Z, MacDermid JC, Ham H. Test-retest reliability and validity of normative cut-offs of the two devices measuring touch threshold: weinstein enhanced sensory test and pressure specified sensory device. Hand Therapy 2014; 2014(19(1)): 3-10. [http://dx.doi.org/10.1177/1758998313515191]

[71] Uddin Z, MacDermid JC. Quantitative sensory testing in chronic musculoskeletal pain. Pain Med 2016; pnv105. [Epub ahead of print]. [http://dx.doi.org/10.1093/pm/pnv105] [PMID: 26893116]

[72] Uddin Z. The Power Function of the Ten Test for Measuring Neural Sensitivity in Clinical Pain or Sensory Abnormalities. In: Proceedings of Singapore Health Care: [Published online]. 2016 [http://dx.doi.org/10.1177/2010105816655366]

[73] Uddin Z, MacDermid JC, Packham T. Clinical implementation of two Quantitative Sensory Tests: Cold Stress Test and The Ten Test. Physiother Pract Res 2014; 35(1): 33-40.

[74] Uddin Z, MacDermid JC. A knowledge translation perspective on the two quantitative sensory tests and their usability with clinicians. J Nov Physiother 2015; 5(2): 257.

[75] Rolke R, Baron R, Maier C, et al. Quantitative sensory testing in the German Research Network on Neuropathic Pain (DFNS): standardized protocol and reference values. Pain 2006; 123(3): 231-43.

[http://dx.doi.org/10.1016/j.pain.2006.01.041] [PMID: 16697110]

[76] Berkley KJ. Sex differences in pain. Behav Brain Sci 1997; 20(3): 371-80.

[http://dx.doi.org/10.1017/S0140525X97221485] [PMID: 10097000]

(C) Uddin et al.; Licensee Bentham Open

This is an open access article licensed under the terms of the Creative Commons Attribution-Non-Commercial 4.0 International Public License (CC BY-NC 4.0) (https://creativecommons.org/licenses/by-nc/4.0/legalcode), which permits unrestricted, non-commercial use, distribution and reproduction in any medium, provided the work is properly cited. 